Lexis Vol. XLIII (1) 2019: 117-163

\title{
Lingüística mochica: cuestiones etimológicas y analíticas*
}

\author{
Rita Eloranta \\ Universidad de Leiden
}

\section{RESUMEN}

En este artículo, se revisan algunas etimologías propuestas como mochiquismos; así mismo, se analizan algunos hispanismos que podrían entenderse mejor si se les atribuyera un origen mochica. Además, se discute sobre diversos aspectos gramaticales de la extinta lengua mochica: posesión nominal, clasificación numeral, marcadores de relaciones espaciales, nominalización y paradigmas de futuro. Las reflexiones vertidas en este artículo parten de la lectura del libro de José Antonio Salas García (2012) Etimologías mochicas.

Palabras clave: Mochica, etimología, posesión nominal, clasificación numeral, marcadores de relaciones espaciales

\footnotetext{
*Agradezco a Luis Miguel Rojas-Berscia por haber revisado la primera versión de este trabajo. A José Carlos Huisa Téllez y a Diego Armando Marquez Arnao gracias especiales por revisar y comentar al detalle las últimas versiones. Este trabajo fue subvencionado por el Consejo Europeo de Investigación (FP7/2007-2013, ERC Advanced Grant $N^{\circ} 295918$ ).
}

https://doi.org/10.18800/lexis.201901.004 


\section{AbSTRACT}

In this article, I examine some previously proposed etymologies of words of Mochica origin. In addition, I discuss certain hispanicisms that would be better understood when seen as stemming from Mochica. To this end, I also discuss diverse grammatical aspects of the extinct Mochica language: nominal possession, numeral classification, spatial relation markers, nominalization and future paradigms. The reflections I offer here are based on José Antonio Salas's (2012) book entitled Etimologías mochicas.

Keywords: Mochica, etymology, nominal possession, numeral classification, spatial relation markers

El mochica, idioma norperuano que en tiempos coloniales gozó del privilegio de ser considerado una lengua general, tanto por su importancia como por su difusión, constituye un enigma y a la vez un reto para los lingüistas de hoy. Los rasgos tipológicos peculiares del mochica lo distancian de los demás idiomas andinos y lo recluyen a la categoría de lengua aislada. ${ }^{1}$

A pesar de ser el mejor documentado de los idiomas de la costa norte, la información que se tiene sobre el mochica es limitada, razón por la cual todos los esfuerzos de los investigadores contribuyen de manera especial a su mejor entendimiento, así como a su posible sistematización y reconstrucción interna. Una óptima aproximación a esta lengua podría acercar a sus investigadores hacia una propuesta plausible respecto a su filiación genética o sus posibles relaciones externas.

Dos factores fundamentales dificultan el trabajo del estudioso del mochica. En primer lugar, la única descripción gramatical existente, elaborada por Fernando de la Carrera, se remonta a 1644, cuando todavía era una lengua viva. Esta gramática presenta las deficiencias comunes de una obra misionera; por ejemplo, se observa cierta falta de sistematicidad y la tendencia al encajonamiento forzado de

\footnotetext{
Las observaciones y los comentarios que siguen han sido motivados por el libro Etimologías mochicas, del lingüista José Antonio Salas (2012), quien viene publicando desde 2002 numerosos trabajos, producto de su esfuerzo en el estudio y análisis de la extinta lengua.
} 
la descripción gramatical según el modelo grecolatino. Pese a estas carencias, constituye una fuente rica de datos de diversa índole, ya que ofrece, además de la información gramatical, información cultural, etnográfica e histórica acerca de una región mochicahablante específica ${ }^{2}$ hacia fines del siglo XVI e inicios del XVII.

El segundo factor que complica la tarea de los interesados en investigar el mochica es la falta de un estudio comprensivo. Los trabajos conocidos hasta el momento no parecen estar integrados en un sistema que responda y explique el mochica en su totalidad. Por lo demás, no se ha descrito el idioma desde sus características propias, sino que se ha tratado de encasillarlo en modelos gramaticales generales. Por ejemplo, respecto al sistema de posesión nominal del mochica, se puede observar claramente, en Hovdhaugen (2004) y Salas (2012), que no se ha realizado un análisis exhaustivo a partir de la lengua misma. ${ }^{3}$

Entre otros rasgos atípicos del mochica, también podemos mencionar su sistema de clasificación numeral, que se asemeja más a "sistemas de cuenta específica"4 encontrados en Polinesia y Micronesia (cf. Bender y Beller 2005, 2006a, 2006b, 2007a y 2007b) que a sistemas de clasificación numeral encontrados en lenguas de América del Sur. Creemos que el sistema de clasificación numeral de esta lengua se entiende mejor si lo consideramos en una fase de transición entre un sistema de clasificación numeral en sentido estricto y otro de cuenta específica. ${ }^{5}$

\footnotetext{
2 Podemos afirmar que la variedad de mochica que se describe en el Arte de la lengua yunga (1644) corresponde especialmente a la zona de Reque, en donde misionó Fernando de la Carrera.

3 Después de un análisis exhaustivo (Eloranta en prensa/a) se puede concluir que el mochica exhibe, por ejemplo, una distinción especial de inalienabilidad que no se puede identificar como un sistema bipartito estricto, sino más bien como un continuum formal que corresponde icónicamente a la distancia relacional (conceptual) entre el poseedor y el objeto poseído. De esta manera, en un extremo del continuo se ubica la construcción posesiva más arcaica del sistema —es decir, la correspondiente a posesión inalienable, mientras que las de posesión alienable — esto es, las construcciones más innovadoras- se ubican hacia el otro extremo.

4 “Specific counting systems" (Bender y Beller 2006a: 380).

5 Un análisis más amplio del sistema de clasificación numeral del mochica se ofrece en Eloranta (en prensa/c).
} 
Puede decirse que, en Etimologías mochicas (Salas 2012), el autor se embarca en la fascinante, pero complicada tarea de desentrañar "biografías de las palabras". ${ }^{6}$ El libro consta de una introducción y cuatro capítulos. El primero se ocupa de los peruanismos que el autor considera de origen mochica. El segundo desarrolla el tema de los hispanismos analizados como préstamos ocultos en dicha lengua. El tercero versa sobre los términos del mochica que han ingresado en campos específicos de saberes determinados de la cultura peruana. En el último, el investigador ofrece la reconstrucción de algunos elementos morfológicos y sintácticos de la lengua.

El presente ensayo sigue el orden del libro de Salas (2012). Se organiza de la siguiente manera: en la sección 1 se revisan y cuestionan brevemente las propuestas de algunos peruanismos asumidos como de origen mochica [1.1], se analiza y critica lo expuesto acerca de chumado [1.2] y se examina de cerca la propuesta de pallar [1.3]. En la sección 2 se hacen observaciones en relación con dos supuestos hispanismos presentes en la lengua, y que, según el presente análisis, parecen ser más bien mochiquismos: <chach> [2.1] y <chucæss> [2.2]. En la sección 3, se presentan algunos cuestionamientos frente a ciertas propuestas y aproximaciones del autor referentes a algunos aspectos morfosintácticos de la lengua mochica: posposiciones correspondientes a las partes del cuerpo [3.1], la realización del esquema del contenedor [3.2], clasificadores numerales de la lengua mochica [3.3] y paradigmas de futuro [3.4]. La sección 4 se limita a una breve síntesis y discusión final.

\section{Revisión de peruanismos de origen mochica}

En el capítulo 1 del libro, se examinan los aspectos formales y de contenido de nueve peruanismos que el autor considera mochiquismos: checo 'calabazo pequeño', cholo 'muchacho', chumado 'borracho', cuculi 'paloma', faique 'tipo de árbol', lapa 'mitad de calabaza que

\footnotetext{
6 'Word biographies', traducción que Malkiel (1993: ix) hace de bistoire de mots, de Alfred y Antoine Meillet.
} 
se utiliza como tina', maneje 'acto sexual', pallar 'Phaseolus lunatus' y poto 'recipiente para chicha' y 'trasero (de una persona)'. A pesar de que numerosos aspectos del análisis presentado a lo largo de este primer capítulo merecen mayor atención, comentaremos aquí solo algunos, que no parecen tener un sólido fundamento lingüístico.

1.1. La etimología de cuculí que Salas (2012) ofrece no se discutirá al detalle aquí, pero sí es necesario cuestionar, para una posterior profundización en el tema, la presencia de acento final que no encaja con el acento inicial típico del mochica ${ }^{7}$ (42-45). Salas (2012) sostiene que la palabra cuculi se encuentra tan ampliamente difundida en la costa norte que aparece en su literatura costumbrista (42). Para justificar su observación, cita un fragmento del relato breve Por arriba y por abajo, de León y Paredes (1934): “En efecto; tomó en una mano el frasco de cucharadas, y en la otra el de lavativas, y levantando aquel hasta el ojo derecho de la 'compañera', le dijo: -Éstas, por la boca; y poniendo el otro pomo cerca de la cintura, añade: y éstas por el cu... cu... lî”. ${ }^{8}$ Sin embargo, resulta claro que, en ese fragmento, cuculí no se refiere a la paloma de párpados azules, sino más bien, en sentido eufemístico, al recto, por culo, a través del cual se aplican las lavativas o enemas, tema del relato. Esto solo prueba que la palabra es conocida, pero no se puede descartar que sea utilizada como eufemismo también fuera de la costa norte. En este sentido, Marquez Arnao, en comunicación personal, sugiere revisar Juan de Arona (1884: 138) —a quien Salas cita-. Arona ofrece una datación más temprana para cuculí en la literatura costumbrista del sur andino, pues incluye dos extractos de la novela del cuzqueño Narciso Aréstegui, El padre Horán: escenas de la vida del Cuzco (1848) ${ }^{9}$, como ejemplos del uso literario de cuculí en su Diccionario de peruanismos: "Entre los objetos que rodeaban á

\footnotetext{
7 Sobre el régimen acentual del mochica, véase Cerrón-Palomino (1995: 133-138). Sobre el acento inicial en la lengua mochica, véase Hovdhaugen (2004: 14).

8 Énfasis en León y Paredes (1934: 19) y en Salas (2012).

9 La novela de Aréstegui fue publicada como folletín en el diario El Comercio entre agosto y diciembre de 1848 .
} 
Angélica se hallaban sus canastas de costura, y en otra más pequeña la cuculí que le había obsequiado su hermanito, amarrada de los pies con una cinta carmesí. [...] Angélica no había reparado en ellos, porque absorbia toda su atención la cuculí, que no cesaba de dar vueltas sobre la baranda."

Así mismo, merece un comentario la explicación que ofrece Salas acerca de la formación del pronombre moiñ al esbozar su hipótesis de que en el mochica surgen diptongos como resultado del contacto con consonantes palatale ${ }^{10}$ (2012: 46). Un caso sería el de faichcass, que derivaría en faique, y propone pensar en otros casos, como el de la formación del pronombre de primera persona singular <moiñ $>$ : “moix = 'alma', ei $\tilde{n}=$ 'quién', moiñ = 'yo'” (Salas 2012: 46). Este tipo de análisis no resulta plausible, pues el autor se basa en la relación entre 'yo' y 'alma', lo que supone para moin una carga cristiana que no debe de haber tenido en mochica. Más interesante es pensar que $<$ moiñ $>$ esté relacionado con el determinativo <mo $>$ 'este' y el clítico de primera persona $<=$ eiñ $>$, una suerte de 'este soy' o 'soy este'.

A continuación, no solo cuestionamos la etimología mochica del peruanismo lapa (Salas 2012: 48-51), sino que, además, pretendemos deslindar las palabras mochicas de las de la lengua norperuana quingnam a partir del acento final atípico en las palabras mochicas. Dado que la costa norte fue escenario de interacción de distintas lenguas y bilingüismo - lo que se desprende también de las afirmaciones de Calancha (1638: 550)—, bien se puede postular que <lapà> (Carrera 1644: 104) no haya sido mochica sino más bien quingnam, que parece tener la tendencia de presentar acento final en sus palabras, muy distinto del acento inicial en el mochica. Lo mismo ocurre con <patà> (Calancha 1638: 553), divinidad compartida por los pacasmayos - presuntamente de lengua quingnam- y los yungas de lengua mochica: por el acento final se puede postular que $<$ patà $>$ no es mochica.

\footnotetext{
10 “Típicamente, las consonantes palatales mochicas producían a nivel fonético un segmento vocálico palatal que formaba un diptongo con el núcleo silábico que antecedía a la consonante palatal” (Salas 2012: 46).
} 
Salas (2012) sostiene que, en mochica, hay algunas otras palabras más de acento agudo: <yanà> 'criado', <munà> 'anciano' y $<$ patà> 'las Marías', y no contempla la posibilidad de considerar que estas palabras tienen un origen distinto del mochica (49). <yanà> 'sirviente' es una palabra de origen quechua (Cerrón-Palomino 1995: 119-120). Además, el registro temprano de <munà> —atestiguado en el patronímico de don Cristóbal Saguanchi Munao, cacique de Moche en 1593 (Zevallos Quiñones 1992: 144)— sugiere que el origen del término es muy probablemente quingnam. Ya Cerrón-Palomino había considerado, además, que la relativamente frecuente presencia del fonema labiovelar /w/, ajeno al mochica, podía ser un elemento diagnóstico para determinar qué palabras o topónimos pueden o no ser de origen quingnam (1995: 40). De este modo, a pesar de que este mismo autor había establecido desde hace mucho tiempo que $<$ munà $>$ era de origen quingnam (Cerrón Palomino 1995: 40), Salas (2008b: 211-222; 2012: 123-129), por su lado, propone que el término se origina del mochica $<$ munà $>$ (Carrera 1644: 13) o <mena> (Middendorf 1892: 58), quien lo traduce como 'abuelo'. Carrera registra dos términos <munà, munâio. l. munang ô> (1644: 13), hecho que podría revelar que el término era, en efecto, quingnam originalmente, ya que la marca relacional <-ang $>$ de $<$ munang $>$ (cf. Eloranta en prensa/a) mostraría una mochiquización del quingnam $<$ munà $>$ al elidirse la vocal final $<$ à $>$ y permitir así la entrada del término como $<$ mun- $>$. Teniendo en cuenta las escasas palabras con acento final de supuesto origen mochica, ¿por qué no pensar más bien en un origen quingnam?

Por otro lado, a propósito de su análisis sobre $<$ maneje>, Salas busca explicar cómo un derivado del verbo $<$ man-> puede cumplir múltiples funciones, sin advertir la importancia del sufijo nominalizador $\left\langle-V_{c}\right\rangle$ (2012: 53). Este es un elemento altamente productivo y versátil, características que, desde un punto de vista translingüístico, no son extrañas, ${ }^{11}$ y debería incluirse en un análisis

\footnotetext{
11 Yap, Grunow-Hårsta y Wrona dan, por ejemplo, evidencia de nominalizadores versátiles en diversas lenguas asiáticas, como el chantyal, el chaizhou, el chino mandarín, el
} 
del sistema de nominalizadores léxicos ${ }^{12}$ del mochica, al que tampoco recurre Salas.

El sufijo $<-\mathrm{Vc}>$ se usa para formar nominalizaciones deverbales de lugar, instrumento y agente. Al considerar, entonces, el verbo mochica <man-> 'beber, comer', se puede identificar (i) <man-ic $>$, nominalización instrumental o locativa, como 'poto, contenedor para beber o comer'; (ii) <man-ic >, nominalización de lugar 'lugar de deshonestidades, lupanar' y 'comedor' o (iii) $<$ man-ic $>$, nominalización agentiva 'hombre o mujer sensual', como se puede ver ya en Carrera (1644: 5). El ejemplo (1) muestra la versatilidad de la nominalización obtenida con el nominalizador $<-\mathrm{Vc}>$ :
(1) $<$ manic $>$
man-ic
beber-NMLZ
'poto, contenedor para beber o comer, hombre o mujer sensual, lugar de deshonestidades, lupanar, comedor'
(Carrera 1644: 5)

En relación con la etimología de <poto> propuesta por Salas, cabe cuestionar la manera en la que cita sus fuentes (2012: 60-65). A continuación, entre comillas, aparece el fragmento que se incluye en Salas (2012: 61); la fuente de la cita es el manuscrito original del vocabulario mochica compilado por Brüning durante 1905-1924 y consignado como Brü 1.35:

"Játu polének, llerkete poto, ¿ichérr? Texto original piel barriga desnudo testículo qué-con Traducción de palabras Barriga de pellejo, cojones desnudos, ¿con qué? Traducción libre”

Frente a esta, tenemos la cita original (Brü 1.35., Mochica II: 15):

“Játu polének, llerkete poto, ichérr=

japonés, el coreano y el cantonés (2011: 4).

${ }_{12}$ Para un análisis completo del sistema de nominalizadores léxicos del mochica, consúltese Eloranta (en prensa/b). 
Barriga de pellejo, cojones desnudos, con qué?

Se dice à uno que, sin tener plata, quiere jugar al grande”.

En este caso, queda claro que tanto la traducción de palabras como la traducción libre son de Salas, quien debería especificarlo, porque el lector podría confundirse y asumir que la cita y las traducciones son de Brüning.

\subsection{Chumado}

Salas examina el vocablo chumado (2012: 40-42), reportado en el norte del Perú y consignado en diccionarios regionales como el Diccionario de piuranismos de Puig ([1985] 1995: 73), el Vocabulario de peruanismos de Ugarte Chamorro (1997: 95), el Diccionario de peruanismos de Álvarez Vita (1990: 208) — que indica la zona de su uso: Piura en el Perú, el noroeste argentino, y las provincias andinas y el norte del Ecuador-y el Diccionario de piuranismos de Arámbulo (1995: 79), que indica que chumado o shumado se usa en la sierra de Piura, sobre todo en la parte cercana al Ecuador.

Así mismo, Adelaar (en Adelaar y Muysken [2004] 2007: 61) menciona que la voz chuma 'beber' se usa en Colombia, para lo cual cita a Ortiz (1946), quien hace notar que chuma se usa en el español del sur de Colombia para hacer referencia a 'borrachera' y sugiere que puede tratarse de un préstamo del yurumangui (25). Adelaar (en Adelaar y Muysken [2004] 2007), sin embargo, apoyándose por un lado en la evidencia de la distribución en el norte del Perú y el Ecuador y, por otro, en la semejanza del término con el mochica $<$ cuum-> 'emborrachar', propone un origen mochica (61).

El Diccionario de americanismos (2010) registra la entrada chumado,-a como 'persona borracha' e indica su uso en Colombia, ${ }^{13}$ el Ecuador, Bolivia, y el noroeste y el oeste de la Argentina, además

13 El CREA ofrece un caso en el que chumar 'embriagarse' se considera expresión del pastuso (de Pasto) en Colombia. Además, en el corpus del Nuevo diccionario histórico del español (2013), se encuentra el uso de la palabra abumarse para 'embriagarse'. Comenta Suárez (1923-1927): 
de registrar una forma popular: achumado. ${ }^{14}$ Corominas ([1954] 1984), por su parte, indica que chumarse se conoce en la Argentina y el Uruguay (407). Más aún, Amaro Gamboa consigna chumar 'emborrachar', 'embriagar', chumarse 'emborracharse', estar chumado 'estar borracho' y establece su extensa difusión incluso hasta la zona de Yucatán, en México (1999: 302). Este mismo autor menciona que se trata de un “campechanismo” poco usado en Yucatán, donde es más frecuente utilizar tomado como el equivalente de chumado (Amaro Gamboa 1999: 302).

La primera propuesta de un posible origen mochica de chumado proviene de Puig ([1985] 1995), quien consigna en su diccionario la voz chumadito y propone el étimo mochica chumapoec ${ }^{15}$ 'borracho' (73). A partir de esta propuesta, Salas (2012) diserta sobre el posible origen mochica de chumado con el objetivo de justificarlo (40-41). En resumen, fundamenta su argumento sobre las formas <cyum-> y <cyæm-> 'emborrachar', que, según Carrera (1644), podemos segmentar a partir de <cuumepeiñ $>$ y <cчæmepeiñ $>$, respectivamente. Después del análisis de los ejemplos (2) y (3), ambas formas pueden ser traducidas como 'yo me emborracho'.

(2) <cyumepeiñ > cyumemborrachar'yo me emborracho'
(Carrera 1644: 66) ep $=\quad$ eiñ PASS $=\quad 1 \mathrm{PS}$

"Ahumarse dicen en Cuba por embriagarse, relacionando la palabra con humo, aun cuando ella viene de chuma y chumar (beber), palabra que se trocó en jumar, en virtud de la conversación de las dos consonantes, como en Quichote y Quijote”.

14 Rodolfo Cerrón-Palomino, en comunicación personal, nos alcanza el siguiente comentario: "En el cap. VII, del Libro V, de la Historia del Nuevo Mundo, allí donde el autor se ocupa de la <achuma>, especie de cardón nativo, desliza el editor Francisco Mateos una nota al pie de página, en la que dice: 'Del nombre de esta planta deriva indudablemente el verbo actual criollo del Perú y Chile chumarse, sinónimo de emborracharse, embriagarse"” (Cobo [1653] 1964: libro V, cap. VII, nota 5, p. 205). Es obvio que se trata de una etimología popular, como se adelanta en señalar el mencionado estudioso. 15 Carrera (1644) registra <cqumapæc> 'borracho'. <cчumapæc> es segmentable en $<$ cqum- $>$ y $<-(\mathrm{V}) \mathrm{pVc}>$, que es un nominalizador agentivo (Eloranta en prensa/b). Salas (2012: 41) llama a este sufijo "participio activo" (41). 
(3) <cцæmepeiñ> cyumemborrachar'yo me emborracho'
(Carrera 1644: 157)

ep $=\quad$ eiñ

PASS $=\quad 1 \mathrm{PS}$

Por su lado, Salas propone que los hablantes bilingües fueron capaces de identificar esta raíz a pesar de que todas las evidencias encontradas en la obra de Carrera solo registran la forma derivada <cyumep-> 'emborracharse' (2012: 41). Luego de haber identificado esta raíz, los hablantes probablemente sufijaron el morfema de participio del español a la raíz identificada <cyum-> y de esta manera obtuvieron chumado.

Frente a la propuesta de Salas, aparentemente válida, presentamos una contrapropuesta que esbozamos a continuación. En primer lugar, una de las razones por las que cuestionamos el origen mochica del término es su amplísima distribución, que, como se puede apreciar, llega hasta Yucatán en México y el Uruguay en América del Sur. Por lo demás, chumado se conoce especialmente en Piura, en el Perú, pero no en Lambayeque, donde se esperaría una presencia algo más prominente de términos mochicas.

Además de estas razones, la evidencia de la existencia de este término en el léxico castellano, asturiano y gallego acusa su origen fuera del ámbito mochica. En su Diccionario castellano, Terreros y Pando (1786) consigna la entrada chumar como 'vulgarmente lo mismo que beber vino' (424). En el Vocabulario de Riosa, de Álvarez Fernández-Novo, se encuentra el término chumar ${ }^{16}$ como 'emborracharse' y 'beber bebidas alcohólicas' (Álvarez FernándezNovo 1998: 57). En el Diccionariu de la llingua asturiana (2015), aparece prácticamente lo mismo. ${ }^{17}$ En el estudio del burón, jerga de los vendedores y albarderos ambulantes de Forniella- de

\footnotetext{
16 “tomar bébores alcohóliques. Enfilarse, moñarse, emborracharse” (Fernández-Novo 1998: 57).

17 chumar: v. fam. 1. Beber [bebíes alcohóliques davezu]. 2. Beber [bebíes alcohóliques en gran cantidá].
} 
Álvarez López (2005), ${ }^{18}$ también se hallan más argumentos para asumir que el término esté muy probablemente relacionado con el asturiano (148). En burón, existen varios vocablos que provienen del asturiano, como el verbo chumar que significa 'beber'19 (Álvarez López 2005: 128; 148). Sin embargo, el mismo Álvarez López (2005) menciona que el burón comparte numerosos vocablos con jergas gallegas; específicamente, comparte el verbo chumar con la jerga de Tierra Montes (138). Esto no quiere decir, sin embargo, que el origen de chumar sea esta jerga del gallego, pero sí es una clara invitación a consultar el Diccionario galego-castelán e vocabulario castelán-galego, según el cual chumar significa 'beber' en la jerga de los canteros de Pesqueiras (Franco Grande 1968: 306). A pesar de estas referencias que nos llevan hacia el gallego, parece evidente, dada la información lexicográfica, el origen asturiano ${ }^{20}$ de chumar y chumado.

Todo indica que chumar y chumado tienen una amplia distribución en diferentes lugares de América y la Península. Postular un origen mochica de estos términos no parece adecuado. El origen peninsular — ya sea del castellano, del asturiano (o del gallego)_ parece más plausible y puede explicar de mejor manera su presencia en las diferentes variedades regionales de los países latinoamericanos mencionados. Personalmente, nos inclinamos a asumir que el vocablo es un asturianismo.

18 Eh, mañóis ¿chumamus a arrancadera? “Eh, paisanos, ¿bebemos la última?” (Álvarez López 2005: 148).

19 Chumadera 'copa de licor'; chumaderas 'copas en el juego de cartas'; chumadero, chumadeiro 'bebedero'; chumeta 'la bebida'. Todos estos son términos consignados en Álvarez López (2005: 148).

20 En relación con el casi seguro origen asturiano de chumar, se encuentra otro término de origen asturiano que se usa en el norte del país. En comunicación personal, Luis Andrade Ciudad expone que, en la sierra norteña - Cajabamba, Huamachuco, Otuzco y Pallasca-, es de uso frecuente un término que él consideraba inicialmente de origen culli; le resultó sorprendente descubrir, en este caso, que el término se encuentra registrado en el asturiano. El término en cuestión es poña 'pelusa, resto de las espigas después de la trilla, resto vegetal pequeño’. Este hallazgo de Andrade Ciudad y la contribución ofrecida acá en relación con chumado invitan a investigar más términos asturianos que puedan haber entrado al léxico del norte del Perú. 


\subsection{Pallar}

Torero (2002: 229) establece la relación entre el segmento incluido en la voz <ñam paxllæc> 'Lambayeque' (Carrera 1644: 129) y $<$ pexllæc $>$, elemento sin traducción que forma parte de la frase representada en (4):

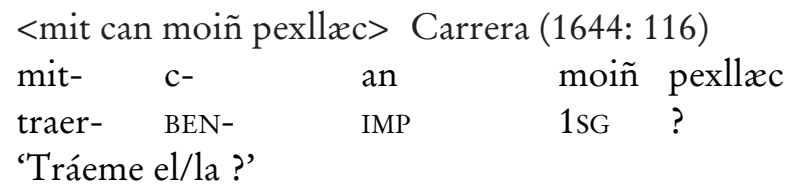

Según Torero, ambas voces, $<$ paxllæc $>$ y $<$ pexllæc $>$, corresponden al nombre mochica del Phaseolus lunatus, que se conoce en la región como 'pallar', cuyo origen asume quechua. ${ }^{21} \mathrm{~A}$ su vez, Cerrón-Palomino (2008) también acepta que la voz <paxllæc> está presente en los nombres dinásticos mochicas, como se puede apreciar en $<$ Ñaimpaxllæc $>,{ }^{22}$ y comenta, además, que la variante $<$ paxllær $>$, derivada hipotéticamente de <paxllaec $>$, debe de ser el origen de la voz pallar que conocemos (157). En la misma dirección avanza Salas, quien busca justificar tal posición sobre la base de dos argumentos que presentamos a continuación (2012: 59).

El primero se fundamenta en el origen y la antigüedad del cultivo del pallar, para lo cual nuestro autor cita a Brack, quien indica que el pallar posiblemente sea oriundo de la costa peruana y fue sido domesticado hace 7300 años (Brack 1999: 382).

El segundo argumento se basa en "el reconocimiento que se hace en la obra de Diego González Holguín ([1608] 1952: 528) del germen costeño del pallar, el cual define como los 'frisoles de los yungas delgados y anchos'” (Salas 2012: 59).

\footnotetext{
21 Torero (2002): “es el nombre mochica correspondiente al quechua pallar” (229). Énfasis del propio Torero.

22 Cerrón-Palomino consigna <Ñaimpaxllæc > (2008: 157); y Carrera, <Ñampaxllæc > (1644: 129).
} 
En relación con el término $<$ paxllæc $>$, consideramos de importancia consignar una tercera voz que bien podría contribuir con la dilucidación de $<$ ñampaxllæc $>$ (Lambayeque). Uno de los numerosos textos no traducidos que se encuentra en la obra de Carrera es la oración de Salve Regina (Carrera 1644: 209-210). En esta plegaria, parece haberse registrado la evidencia del verbo que da origen a la nominalización que representa $<$ paxllæc $>$. Hasta el momento, este verbo nunca había sido mencionado por los investigadores del mochica. En (5), se aprecia el verbo <paxll-> que podría significar 'volver', 'retornar', 'dirigir(se)':

(5) < paxll con mæich totna aio chang ñicopæco locy> (Carrera 1644:210) paxll- c- on mæich totna aio chang volver/dirigir- BEN- IMP 1PL hacia DEM.DIST 2sG.POS.

$\begin{array}{lll}\text { ñico- } & \text { pæco } & \text { locy } \\ \text { hacer el bien } & \text { NMLZ.AG } & \text { ojo }\end{array}$

Lit. 'Vuelve a nosotros esos tus ojos que hacen bien' 'Vuelve a nosotros esos tus ojos misericordiosos'

Teniendo en cuenta esta evidencia, es muy probable que el topónimo que refiere a Lambayeque no haya tenido que ver con la voz que conocemos como pallar como había sugerido Torero (2002: 229). $<$ Paxllæc $>$ es segmentable en $<$ paxll-æc $>$, donde se puede advertir el sufijo nominalizador $\langle-\mathrm{V} c\rangle$, mencionado anteriormente. Debido a que este sufijo puede ser utilizado para crear nominalizaciones deverbales de lugar, tanto agentivas como instrumentales (Eloranta en prensa/b), <paxllæc > podría significar, por ejemplo, 'el lugar del retorno' o 'el que retorna'. A raíz de esta identificación, no nos parece adecuado considerar $<$ paxllæc $>$ y $<$ pexllæc $>$ como correspondientes del mismo término. La etimología de <ñampax$1 l æ c>$ con un segmento <paxllæc $>$ que significara 'el que retorna' o 'el lugar de retorno' adquiriría un matiz interesante si se tuvieran en cuenta las leyendas de fundación de las dinastías gobernantes 
del norte que implican la llegada de un personaje desde un lugar lejano. ${ }^{23}$

Por lo demás, es posible encontrar en diferentes fuentes coloniales el vocablo que refiere a pallar. El registro más temprano se encuentra en el vocabulario de Santo Tomás, donde no solo se registra la entrada $<$ pallar $>,{ }^{24}$ sino que se hace referencia incluso a la chacra de pallares o hawar: <pallarpachacara> (1560: 159). Este registro temprano en la obra de DST motiva a reflexionar sobre el posible origen quechua chinchaisuyo del término.

Otro registro temprano del término, con información adicional que apoyaría la idea de que dicho vocablo sea un chinchaisuyismo, se presenta en Valera, quien registra en la entrada de 'pallar': "frisoles grandes como hauas (Chin.)” (1586: sin numerar). La misma referencia parece repetirse en las siguientes ediciones de esa obra y de otras obras posteriores; así, se advierte en Valera (1603: sin numerar), (1614: sin numerar) y en la más nueva edición de Valera: ([1586] 2014: 142). En la edición de la misma obra realizada por Martínez, se registra "Frisolos [sic] grandes como hauas, (Chin.)" (1604: sin numerar).

Todo esto se ve reforzado con la evidencia proporcionada por Torres Rubio (1700) tanto en su Vocabulario Indico Chinchaisuyo (Torres Rubio 1700: 54v-57v) como en su Vocabulario Castellano, Indico Chinchaisuyo (Torres Rubio 1700: 57r- 59r). En estos casos, se consigna también la abreviatura (Chin.), que aclara un origen chinchaisuyo.

Una referencia más que hace sospechar un origen chinchaisuyo del vocablo pallar se encuentra en el Vocabulario de la lengua Chinchaisuyo, y algunos modos mas usados de ella, que compuso $y$ añadio al antiguo (Figueredo 1754: 213r-224r) y el Vocabulario segundo de la Lengua Chinchaysuyo, del Castellano al Indico (Figueredo 1754: 225v-231r). En Figueredo, se lee "Estas reglas, y

23 En relación con $<$ ñam $>$, resulta de sumo interés y provecho revisar el artículo de Rojas-Berscia y Ghavami-Dicker (2015).

24 pallar: haua, legumbre (Santo Tomás 1560: 159) pallarpachacara hauar (Santo Tomás 1560: 159) 
Vocabulario Chinchaysuyo, que añadiò al Arte el P. Juan de Figueredo, las vio un Padre Misionero, que por las repetidas Missiones con que hà corrido todo el Arzobispado de Lima, donde mas se usa la Lengua Chinchaysuyo, està mubien instruido, y practico en dicha Lengua..." (1754: 214v-214r). Esta aclaración confirma, a su vez, que definitivamente los vocablos registrados en este vocabulario podrían ser, en efecto, chinchaisuyismos. En la entrada para $<$ pallar> (Figueredo 1754: 222r), queda registrado: "frijoles, que aca llaman pallares", mientras que en la entrada de frijoles se consigna $<$ pallar> (Figueredo 1754: 227v).

El registro del término en fuentes tempranas, con la respectiva aclaración de que se trata de un chinchaisuyismo, es sugerente. Sin embargo, el hecho de que pudo haber sido un chinchaisuyismo no implica necesariamente que se trate de un término quechua, con lo cual queda abierta la posibilidad de que haya sido un término mochica.

\section{Hispanismos ocultos en la lengua mochica}

En esta sección, discutiremos solo dos términos - $2.1<$ chach $>$ y $2.2<$ chucress $>$ - que Salas considera hispanismos, pero que, según nuestra propuesta, parecen exhibir un origen mochica.

Salas (2012) trabaja algunos vocablos que considera hispanismos introducidos al mochica (67-106) y los divide entre "préstamos efectivos y creaciones ad hoc" (67). Los ocho vocablos de este segundo grupo, que el autor también denomina "pseudopréstamos", son identificados acertadamente por él como una serie de datos falsos ofrecidos a Larco Hoyle (1939) durante su trabajo de campo. Entre los "préstamos efectivos", Salas lista los siguientes: <casaro> 'casado'; <chach> 'muchacha', 'hija'; <chucxss> 'choquezuela'; <diviopadam> 'marido'; <fak> 'vaca'; <fenek> 'último hijo'; <javan> 'cerdo'; <jjívo> 'encía'; <kachi> 'cuerno'; <káju> 'pavo'; $<$ káksuk> 'cacho' 'cuerno'; <kŏ́jpa> pantalón; <kóstaj> 'costal'; <palja> 'olla'; <patkon> 'patacón'; <plantan> 'plátano'; <poye> 'banco de barro'; < rrel $>$ 'real' y < singang $>$ 'ciénaga'. 


\subsection{El vocablo $<$ chach $>$}

Salas (2012) propone que la palabra <chach > 'muchacha', 'hija' es un hispanismo (71-73). Tiene como referencia el registro de $<$ chach $>$ realizado por Middendorf (1892: 58) e intenta justificar que no se trata de una palabra mochica original debido a que, a pesar de ser un término de parentesco, es presentado con el "genitivo de no posesión" <-är>, y se anima, por tanto, a afirmar que "lo típico es que los nombres de parentesco tengan como opción no marcada el genitivo de posesión - $e$, pues pragmáticamente es más común usar estas palabras con posesivos". Además, Salas cree confirmar la sospecha de que se trata de un hispanismo apoyándose en el registro de Brüning ([1905-1924] 2004: 60) y nos dice: "[...] Brüning [...] brinda dos formas: tšaš y tšaša con la glosa de 'muchacha'[...]” (Salas 2012: 71).

Consultados los manuscritos de Brüning (Brü 1.34 y Brü 1.35), que son los que Salas (2004) edita, como el Mochica Wörterbuch, solo se puede encontrar el registro de ť̌aš. Brü 1.34 consigna "muchacha-tšaš” (Brüning (1905-1924: sin numerar) y Brü 1.35 ofrece "muchacha-tšaš" (Brüning (1905-1924: 36). No hemos podido encontrar la referencia de tšaša en ninguna de las libretas originales de Brüning.

Esta referencia de tšaša es, sin embargo, la que Salas utiliza para sustentar que al parecer ocurrió un caso de análisis morfológico incorrecto: “[...] [e]sto quiere decir que habría segmentado el término 'muchacha' como si fuera la unión de un determinante y un nombre" (Salas 2012: 71). Esto lo explica teniendo en cuenta que $<$ mo $>$ es determinante en mochica. Salas (2012) cita a Corominas ([1954] 1974: 467), quien informa que antes de 1570 se utilizaba 'mochacho'25 en vez de 'muchacho'.

Consideramos que, a partir del análisis del recorrido histórico del término, no se puede llegar a la misma conclusión que Salas, principalmente dada la falta de la referencia de tšaša. Creemos,

\footnotetext{
25 El CORDE ofrece 357 casos de mochacho en 141 documentos cuyas fechas oscilan entre los siglos XIII, y fines del XVI y los primeros años del XVII.
} 
por el contrario, que se debe contemplar que el término mochica $<$ cuechmaed > 'hermana de hermana' parece incluir en su estructura una secuencia reminiscente de $<$ chach $>$. La relación entre $<$ cyech $>$ 'carrillo' y <cyechmaed> 'hermana' es obvia; el segmento <maed> significa 'hacer algo en compañía', según Carrera (1644: 26).

Por lo demás, en relación con el comentario de Salas acerca de que el genitivo de no posesión es atípico para $<$ chach $>$ teniendo en cuenta términos de relaciones de parentesco del mochica, cabe decir que el autor trata de reducir el sistema de posesión nominal mochica según criterios que determinan si un elemento está poseído o no, o asume criterios como tipos de palabras, como en este caso: relaciones de parentesco. En ninguno de los casos, lamentablemente, ofrece una idea global e integrada que conciba un sistema de posesión nominal.

Uno de los rasgos tipológicos de la lengua mochica que la diferencia de las demás lenguas andinas es la presencia de más de un tipo de construcción posesiva. En el libro de Salas, no hay mención a una distinción inalienable/alienable con respecto de las construcciones posesivas. A pesar de que los términos alienable e inalienable son bastante comunes en la literatura, sus referencias son altamente variables, como afirma Nichols (1988: 561). Epps explica que, por esto, Nichols (1988: 572) intenta reconciliar la variabilidad translingüística y propone una jerarquía de pertenencia a la clase de posesión inalienable: (i) términos de parentesco y/o partes del cuerpo, (ii) relaciones parte-todo y (iii) elementos básicos culturalmente determinados, como flechas, animales domésticos, etcétera (Epps 2008: 233). Esta jerarquía, sin embargo, está muy lejos de ser universal (Chappell y McGregor 1996: 8, Epps 2008: 233) y se ve trasgredida con contraejemplos provenientes de diferentes lenguas; es el caso del hup (Epps 2008: 233) o del ewe (Ameka 1995: 147), en los que el orden de esta jerarquía no se cumple.

Dahl y Koptjevskaja-Tamm caracterizan los términos de relaciones de parentesco como "egocéntricos” y "anclados pragmáticamente" (2001: 209). ${ }^{26}$ En un caso normal, un término de

26 “pragmatically anchored” (Dahl y Koptjevskaja-Tamm 2001: 209). 
parentesco se encuentra anclado en el "yo" del acto de habla, esto es, el hablante (Dahl y Koptjevskaja-Tamm 2001: 209). Tipológicamente, se asume que en lenguas en las que existe la distinción alienable/inalienable las relaciones de parentesco son prototípicas del dominio de la posesión inalienable; sin embargo, no siempre sucede así (Dahl y Koptjevskaja-Tamm 2001: 209). En la lengua dyirbal, los términos de parentesco no son tratados en el ámbito inalienable, sino que pertenecen al ámbito de la posesión alienable (Lyons 1999: 129); en la lengua ewe, las partes del cuerpo son términos de posesión alienable (Ameka 1991: 7).

En este sentido, el criterio de Salas para determinar si un término de parentesco es o no mochica siguiendo solo una "terminación de genitivo de no posesión” es insuficiente. En efecto, algunas partes del cuerpo y las relaciones de parentesco se poseen prototípicamente de manera inalienable, lo que se manifiesta en la falta de marca morfológica cuando se encuentran en construcciones de posesión; sin embargo, en el mochica el contenido semántico exacto del "set inalienable" es variable, como también se puede ver translingüísticamente en otras lenguas (Aikhenvald 2013: 12). De la misma manera, cabe considerar lo sostenido por Nichols, quien menciona que la noción "inalienable" no es semánticamente uniforme (1988: 572); esto se debe a que la pertenencia a esta clase cerrada varía de lengua a lengua ${ }^{27}$ y se fundamenta en convenciones culturales específicas (Heine 1997: 11).

La propuesta de Salas no considera, pues, esta variabilidad, y carece, además, de un análisis del sistema de posesión nominal de la lengua mochica. Se limita a un criterio simple para establecer los diferentes tipos de estructuras que conforman el complejo sistema de posesión nominal del mochica, que, definitivamente, no puede ser entendido como un sistema bipartito estricto. En el caso específico del mochica, la categoría inalienable abarca términos de relaciones de parentesco, relaciones de parte-todo, que, a su vez,

\footnotetext{
27 "The notion inalienable is not a semantically uniform one, since the membership of the closed class varies from language to language” (Nichols 1988: 572).
} 
incluyen conceptos de relaciones espaciales, partes del cuerpo y nominalizaciones. ${ }^{28}$ Según las marcas morfológicas presentes en los ejemplos extraídos de Carrera (1644) y teniendo en cuenta los nombres que pueden ser poseídos en estructuras inalienables, existen tres posibilidades: (i) posesión inalienable absolutizable (posesión obligatoria), que implica que el nombre en forma absoluta presente un sufijo <-quic> y que la forma poseída lleve marca cero; esta clase semántica agrupa algunos términos de parentesco de consanguinidad de línea recta. (ii) Posesión inalienable inabsolutizable, en la que la forma absoluta y la forma poseída del nombre implicado no llevan marca. Y (iii), posesión inalienable con doble marcación, tanto en el poseído como en el poseedor.

Con respecto a la morfología de posesión de los términos de parentesco, se puede observar que varía en relación con la distancia conceptual con respecto del ego. Mayor complejidad morfológica implica mayor distancia conceptual. Esta situación se parece a lo examinado por Michael en la lengua nanti (2013: 157-158). De este modo, los términos de parentesco del mochica están al parecer agrupados en diferentes sets. El set más cercano al ego incluiría términos que refieren a padres e hijos, pero en este mismo set estarían incluidos nombres con relevancia cultural como <uiz-quic> 'chacra', <xllon-quic> 'comida', 'pan'. Además, se tendría el set de los términos de parentesco gramaticalizados invariables; y, finalmente, aquellos que se ubican en el campo alienable.

\subsection{El vocablo <chuccess >}

La propuesta que sostiene que < chuccess > es un hispanismo parece ser la que cuenta con menos fundamento. Salas (2012: 73) explica de dónde obtiene la idea de un origen castellano de este término, registrado tempranamente en la lista de partes del cuerpo de Carrera (1644: 179): <chucxss> se encuentra registrado como choquezuela. Salas (2012) relaciona choquezuela y cbueca. El término castellano

28 Lista adaptada de Heine (1997: 10) y Fernández Garay (2004: 47). 
choquezuela es una palabra derivada de chueca; por esta razón, Salas (2012) considera chueca como étimo de <chucæss>.

Según el diccionario académico (2014), choquezuela significa 'hueso en la parte anterior de la articulación de la tibia con el fémur'; y chueca, prácticamente lo mismo: 'hueso redondeado o parte de él que encaja en el hueco de otro en una coyuntura, como la rótula en la rodilla, la cabeza del húmero en el hombro y la del fémur en la cadera'. Ambos términos se refieren, efectivamente, a la rótula. Si bien hay un parecido fonético, la forma <chuccess $>$ responde perfectamente a la estructura de una palabra mochica, como fundamentamos a continuación.

En primer lugar, <chuccess $>$ puede segmentarse en $<$ chuc- $>$ y $<-æ s s>$, como también advierte Salas, quien además reconoce tímidamente que este sufijo <-æss> es "simplemente un morfema de posesión mochica” (2012: 73). Según Eloranta (en prensa/a), este sufijo es uno de los dos sufijos relacionales propios de una construcción posesiva alienable en lengua mochica. En una construcción posesiva alienable, el elemento poseído es no-relacional. Al hablar de nombres alienables, Haspelmath menciona que, por lo general, estos requieren marcación morfológica en una construcción posesiva (2006: 9). Esta marca tiene la función de ser un elemento relacional. Para este fin, en mochica se cuenta con dos sufijos: $<-\mathrm{Vd}>$ y $<-(\mathrm{V})$ ss $)>$. Los sufijos relacionales de posesión alienable $<-\mathrm{Vd}>-$ con las opciones de $<-$ æd $>,<-$ ad $>-$ y $<-(\mathrm{V})$ ss $>$ - con las opciones de $<$-iss $>,<-æ s s>$, <-uss $>$ - se encuentran en distribución complementaria.

La construcción posesiva tiene doble marcación: el poseedor va en genitivo y el núcleo se encuentra marcado morfológicamente con $<-(\mathrm{V}) \mathrm{ss}>,{ }^{29}$ como se aprecia en (6):

29 El grupo de nombres que adquiere este sufijo incluye algunos animales $-<$ fanuss $>$ 'perro' y <felluss $>$ 'pato'-, algunas partes del cuerpo -<chucæss $>$ 'rodilla', <cyætæss $>$ 'corazón' y <potos> 'las turmas'-, además de <ianass $>$ 'criado doméstico', <cuçiass $>$ 'cielo', <xllangmuss > 'enemigo', <choluss > 'muchacho', <melluss > 'huevo', <villos> 'taza', <capcæess > 'posada', <yquiss> 'suegro', <cuilpiss> 'manta' y <ixllæss > 'pecado'. 
(6) <mæiñ cyilpiss> (Carrera 1644: 6)

mæiñ cyilpi-ss

1SG.GEN manta-REL

'mi manta'

El ejemplo (7) representa el caso del mismo nombre 'manta' fuera de la construcción posesiva:

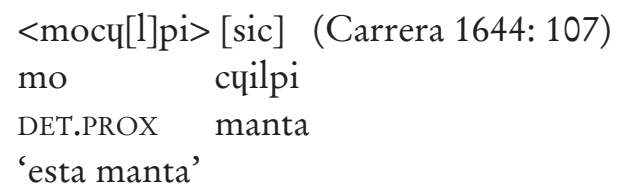

Volviendo a <chucæss> 'choquezuela', hay que considerar que no es sorprendente encontrar términos de partes del cuerpo en el campo de la posesión alienable, lo que se explica teniendo en consideración que, muy probablemente, existían en mochica pares de términos que compartían el mismo referente.

Con la intención de demostrar que en mochica existían pares de palabras con el mismo o similar referente, vale la pena explicar el caso de <cyæt-æss> 30 ‘corazón’ y <pol-quic> 'corazón'. El hecho de encontrar pares de términos de partes del cuerpo que, al parecer, denotan lo mismo, hace pensar que quizás se trate de usos distintos que distinguen entre partes del cuerpo que pueden estar en construcciones posesivas tanto alienables como inalienables. Por

\footnotetext{
30 Parece poco adecuado, por cierto, el comentario a pie de página en Salas, quien al segmentar <cuætæss> se queda con los elementos <cuæt> y <-æss> (2012: 74), y compara la forma de esta raíz con <chät> 'pulpo grande' (Middendorf 1892: 60 y Brüning [19051924] 2004: 11). Según Salas, este último ofrecería <dsöd > tanto para ‘pulpo’ como para 'corazón'. Consignamos aquí las entradas registradas en el manuscrito de la libreta de Brüning: “corazón - çŏ́tas, çet(s), dsöd” y “pulpo - çöt dsöd” (Brü 1.34, sin numerar). Creemos que no es apropiado tomar solo las formas que, en efecto, se parecen para hacer la comparación propuesta. Para Salas, "por una suerte de tropo, la palabra para nombrar al corazón en mochica tenía el mismo origen que el vocablo utilizado para designar a los pulpos" (2012: 74). Aseveraciones de este tipo no nos parecen serias, tanto como parece forzada la relación entre 'corazón' y 'pulpo', pues podría, simplemente, contemplarse la posibilidad de homonimia.
} 
un lado, para referirse a un corazón que puede ser manipulado o extraído —es decir, al órgano mismo-, quizás era necesario usar la palabra más alienable, que en este caso sería <chætæss $>$, dada la presencia del sufijo <-æss $>$, propio de construcciones posesivas alienables.

La otra forma para referirse a 'corazón' y 'bazo' era <pol> (Carrera 1644: 180), que exige la presencia del sufijo <-quic> cuando se encuentra en su forma absoluta, es decir, fuera de una construcción posesiva. Este <-quic> es el sufijo absolutizador, e implica, además, un nombre que puede ser encontrado en una construcción posesiva inalienable. Existe, también, otra considerable diferencia entre $<$ chætæss $>$ y $<$ polquic $>$, que radica en las extensiones semánticas de $<$ pol $>$. En Carrera (1644), se puede encontrar que <polæng > significa 'la varriga, el coraçon, la uoluntad' (116); así mismo, <canpoll-er> aparece como 'con intención', 'adrede ò a proposito' (160) y <peiñ pol-er> 'de buena gana' (103); <pol> puede también ser vientre, pues en los textos religiosos referidos a la Virgen María hay referencias a su vientre (205, 206, 207, etcétera).

Así, pues, a lo largo de los textos de Carrera (1644), <pol-> se usa en relación con deseo, intención, preocupación, voluntad. Es decir, se encuentra en el dominio de elaboración metafórica de la mente y entra en un número de construcciones gramaticales usadas frecuentemente que denotan estados intencionales. ${ }^{31}$

Los casos de pares de términos registrados en el arte, y que según la traducción de Carrera (1644) denotan un mismo referente, nos invitan a reflexionar en que muy probablemente había una distinción entre el uso alienable e inalienable de estos. Los pares de términos de partes del cuerpo citados por Carrera (1644) que sugieren esta reflexión son los siguientes: <lamlam> 'hígado' (180) y <pochæc> 'hígado' (180); <chuc-æss> 'choquezuela' (179) y <nossæn> 'rodilla' (179); y < potos > 'las turmas' (179) y < pelæc > 'las turmas' (179). Siguiendo esta reflexión, no cabe duda de que $<$ chucxss> pudo bien ser de origen mochica.

31 Kockelman discute un caso similar en el q'eqchi (2007: 346). 


\section{Reconstrucción de elementos morfológicos y sintácticos de la lengua mochica}

En esta sección, presentamos algunas críticas al análisis de Salas acerca de algunos aspectos sintácticos de la lengua mochica.

\subsection{Posposiciones correspondientes a las partes del cuerpo}

El apartado 4.3. de Salas se refiere a las "posposiciones correspondientes a las partes del cuerpo” (2012: 146-152). Ya Carrera, en el siglo XVII, presenta las "preposiciones" del mochica y ofrece las más usadas (Carrera 1644: 93-94; 120-123; 161). Debido a que se posponen al nombre que modifican, él mismo sugiere denominarlas “posposiciones”. El término persiste en los trabajos de Middendorf (1892: 96-100), Hovdhaugen (2004: 54-55), Adelaar (en Adelaar y Muysken [2004] 2007: 333) y —como vemos- en el análisis de Salas.

Salas habla de estas posposiciones y sugiere que tienen un valor metafórico para codificar las relaciones espaciales entre objetos (2012: 146). En general, sus observaciones al respecto son bastante acertadas, ya que identifica cuáles son aquellas partes del cuerpo que se utilizan para la función de establecer relaciones espaciales. Sin embargo, consideramos que su análisis carece de una terminología adecuada, que vaya a la par de estudios similares en otras lenguas del mundo. Más aún, el punto de partida de su análisis no parece ser el adecuado. Teniendo en cuenta criterios translingüísticos, podemos afirmar que estos marcadores de relaciones espaciales en la lengua mochica encuentran su base en estructuras de posesión inalienable. ${ }^{32}$

En vez de llamar a estas estructuras "posposiciones de relaciones espaciales", es más apropiado referirse a ellas como "marcadores de relaciones espaciales”. Como asegura Aikhenvald, las marcas de posesión pueden tener otras funciones, significados y extensiones no relacionados con la posesión (2013: 1, 41); de este modo, se

32 Para un análisis más amplio al respecto, consúltese Eloranta (en prensa/a). 
pueden observar partes del cuerpo gramaticalizadas como marcadores de relaciones espaciales. Kockelman constata, además, que "ciertas partes del cuerpo proveen un dominio útil para la codificación gramatical de relaciones espaciales y temporales" (2007: 346). ${ }^{33}$ En esta misma línea, Heine asevera que "[...] [u]na manera común en la que un elemento más léxico y concreto dé origen a una categoría más asbtracta y gramatical es la gramaticalización de términos de parte del cuerpo en marcadores de relaciones espaciales ${ }^{34}[\ldots]$ " (1997: 582).

A pesar de que la ubicación de estos marcadores, presentes en la frase nominal en testimonios del arte de 1644, motiva a llamar estas estructuras "posposiciones", es de mayor relevancia rescatar el hecho de que la mayoría de ellas deriva de nombres de partes del cuerpo, como bien advierten Middendorf (1892), Adelaar (en Adelaar y Muysken [2004] 2007) y Salas mismo (2012). El propio Carrera hace alusión al origen de estas posposiciones (1644: 161). ${ }^{35}$ Carrera (1644) era consciente del origen transparente de las adposiciones del mochica; esto es, de que se habían desarrollado a partir de nombres, que en este caso concreto eran partes del cuerpo. ${ }^{36}$

Según Eloranta (en prensa/a), en relación con la lengua mochica, las partes del cuerpo lexicalizadas como relaciones espaciales se encuentran en el ámbito de la posesión inalienable, hecho que no es ajeno a las lenguas del mundo. Otros estudios apoyan esta aproximación. Así, Lehmann (2003: 86-87) y Ameka (1995: 147)

\footnotetext{
33 "certain body parts provide a handy domain for the grammatical encoding of spatial and temporal relations”.

34 "One common way in which a more lexical concrete item give rise to a more abstract and gramatical category is the grammaticalization of body part terms to markers of spatial relation" (Heine 1997: 582).

35 "Los modos de hablar siguientes son irregulares, y muy vsados, y necessarios, que, aunque cada cosa tiene su nombre de donde estos modos se deriuan, y los nombres dichos son declinables por todos los casos, como no tiene esta lengua preposicion, que signifique en, como en latin in, usase de dichos modos para dezir en".

36 Un caso similar se presenta en Ameka (1995), quien realiza un trabajo de investigación sobre la gramática y significado de las adposiciones del ewe, y propone que el sistema ewe tiene preposiciones de origen verbal y posposiciones de origen nominal.
} 
constatan que las relaciones espaciales son parte esencial de la posesión inalienable. ${ }^{37}$

\subsection{Realización del esquema de contenedor}

En el apartado 4.4., denominado "Realización del esquema de contenedor" (Salas 2012: 153-154), el autor intenta explicar la recurrencia de un sufijo presente en los términos de partes del cuerpo registrados en Carrera (1644: 177-180). Para él, las secuencias $<$ tæec $>$ y <tær > "compartían un mismo elemento lingüístico: -tæ-", al que considera un infijo que interpreta como "recipiente" o "contenedor"; de esta forma, decide, para explicar este caso, valerse de la noción del "esquema del contenedor" como esquema semántico básico que delimita en su interior un espacio. Dice, además, que, a partir de la reflexión de la gramática de Carrera de 1644, infiere y descubre "metáforas ocultas, significados desconocidos y formas que no nos han sido facilitadas de modo explícito" (Salas 2012: 153).

Salas parece interpretar equivocadamente la noción del esquema del contenedor. Según Kövecses (2006), los esquemas de imagen proveen parte importante del entendimiento de nuestro mundo (208-209). Las experiencias corporales que motivan la existencia del esquema del contenedor se pueden reducir básicamente a dos tipos de experiencias: en primer lugar, nuestros cuerpos son contenedores —que contienen órganos y fluidos corporales, por ejemplo-; y, en segundo lugar, nuestros cuerpos no solo funcionan como contenedores, sino que funcionan dentro de objetos más grandes que los contienen, como edificios, lugares, etcétera. La lógica básica de este esquema impone ciertos límites: todo puede estar dentro o fuera del contenedor. Existen muchas metáforas que se basan en el esquema del contenedor: aquellas referidas a los estados, a las relaciones personales y también al campo visual.

\footnotetext{
37 Según Lehmann (2003), esto puede resultar desorientador porque las estructuras de relaciones espaciales carecen normalmente de poseedor y porque su manifestación más obvia es en forma de adposiciones.
} 
Salas no identifica <-tx-> como parte de un sufijo nominalizador de la lengua mochica. A continuación, esbozamos una aproximación que corresponde y explica de manera satistactoria este fenómeno. Esta propuesta contempla $<-\mathrm{t} \mathrm{Vc}>$ como un nominalizador locativo.

En Eloranta (en prensa/b), exponemos que el mochica exhibe un sistema de nominalización tanto léxica como gramatical. Con respecto a los nominalizadores léxicos proponemos un sistema de cuatro nominalizadores, a saber: (i) $<-(\mathrm{V}) \mathrm{c} V \mathrm{Vc}>/<-(\mathrm{V}) \mathrm{ss} \mathrm{V} c\rangle$ nominalizador de evento, como se puede apreciar en $\langle$ læmiçæc $>$ 'muerte', derivado de $<\mathrm{l} x \mathrm{~m}>$ 'morir'; (ii) $<-(\mathrm{V}) \mathrm{pV} \mathrm{c}>$ nominalizador agentivo, como se puede observar en $<$ chicopæc $>$ 'creador', derivado de <chi-co $>$ 'ser-CAUs'; (iii) <-tVc $>$ nominalizador locativo, como en <caxlltxe $>$ 'vejiga', derivado de <caxll-> 'orinar'; y (iv) $\left\langle-V_{c}\right\rangle$, que además de ser un sufijo polifuncional recurrente, es utilizado para crear tanto nominalizaciones deverbales de lugar, agentivas, como instrumentales. De esta manera, $<$ manic $>$, derivado con este sufijo de $<$ man- $>$ 'beber/comer', puede referirse tanto a un recipiente para beber o comer como al lugar para comer o beber (comedor o bebedero).

La crítica que ofrecemos en contra de la posición de Salas se apoya básicamente sobre la justificación de la existencia del tercer nominalizador propuesto, (iii) $<-\mathrm{tV} c>$. Antes de proceder a esclarecer la etimología de $\langle$ caxlltæc $>$, cabe mencionar que el mochica no presenta categorías estrictas de clases de palabras. De este tema nos habla el propio Carrera, cuando explica que "[...] fep, es el sueño, y es nombre substantiuo, y junto con la particula eiñn, que es parte del verbo substantiuo, dize fepein, que en rigor diçe, yo soy sueño, y entienden los Indios esse romance, como de verbo, yo sueño [...]" (1644: 100). Parece, de esta manera, que el mochica presenta cierta flexibilidad en relación con sus clases de palabras, específicamente con la distinción entre verbo y nombre; esta flexibilidad permite comprender que una entrada como <caxll $>$ puede bien ser 'orín', 'orines' u 'orinar'. 
Así, en el caso de <caxlltæc > 'vejiga' (Carrera 1644: 180), derivado de <caxll-> 'la orina' (Carrera 1644: 180) o 'los orines' (Carrera 1644: 100), la etimología de <caxlltæc > parece ser transparente, y podemos sugerir que se refiere a un contenedor o a aquel lugar en el que se contiene la orina. El ejemplo (8) representa la glosa de $<$ caxlltxc >

(8) caxlltæc $>$
caxll- tæc
orinar-NMLZ.LOC
'vejiga'

(Carrera 1644: 180)

La presencia del sufijo nominalizador locativo $<-\mathrm{tVc}>$ se evidencia en diferentes términos de partes del cuerpo, atestiguados con las terminaciones <-tic $>,<-$ tæc $>,<$-tuc $>,<$-tær $>$, <-tærr $>$. Los sufijos <-tær $>$, <-tærr $>$ serían las formas poseídas terminadas en $<-r>$ correspondientes a las nominalizaciones que forman parte de construcciones posesivas, mientras que los sufijos terminados en $<-c>$ son las formas absolutas, es decir, no poseídas.

Mientras que en algunos casos concretos la etimología de los términos de partes del cuerpo es transparente, en algunos otros es imposible establecerla debido a lo limitado del vocabulario conocido en esta lengua. Así, por ejemplo, tenemos que <eiz-tic> 'la madre de la generacion' (Carrera 1644: 180) o 'útero' tiene en su estructura <eiz> 'hijo' y el sufijo nominalizador locativo $<\mathrm{tVc}>$. Debido a la flexibilidad de las clases de palabras mochicas anteriormente comentada, sugerimos que <eiz> también podría ser un verbo relacionado con tener hijos, como bien podría ser 'engendrar'. Podemos, así, concluir que <eiz-tic> sería el 'contenedor donde se engendra' o 'lugar donde se contiene el hijo'. Sin embargo, casos como <cyan-tic> 'párpado', <pi-tær > (<*pitæc>) 'esófago' y $<$ laftic $>$ 'costillas' evocan la idea de partes del cuerpo que se pueden considerar contenedores, pero no sabremos jamás qué significan exactamente. Otros términos de partes del cuerpo con el nominalizador locativo <-tVc $>$, según Carrera, son los siguientes: <al-tærr $>$ 
'garganta', <foc al-tæe ${ }^{38}>$ 'hombro', <xeme-tæe $>$ 'sobaco', <facatæc > 'ingles', <olme-tuc> 'rabadilla', <caxll- tæc > 'vejiga', <eiz-tic> 'útero' y <xllon ${ }^{39}$-tærr > 'estómago'(1644: 177-180).

\subsection{Clasificadores de la lengua mochica}

Salas dedica una considerable extensión al apartado 4.5. de su libro a exponer su análisis de los clasificadores de la lengua mochica (Salas 2012: 154-176). En Salas (2008a), se expone un análisis similar. A pesar de que no se puede negar que en ambos casos ofrece un análisis que tiene sus fundamentos en estudios de lenguas con clasificación numeral, como Aikhenvald (2003) y Allan (1977, 2001), consideramos que no explica bien el sistema en su conjunto. Además, su análisis no incluye todos los clasificadores que el mochica presenta en su sistema de clasificación numeral.

Salas considera $<\mathrm{col}>$ y $<$ ñofæn $>$ "expresiones cuantitativas" o "cuantificadores de palabras" que no forman parte del sistema de los clasificadores del mochica (2008a: 149; 2012: 161-162). Interpreta $<$ col $>$ y $<$ ñofæn $>$ como 'la cantidad de maíz equivalente a la carga de un caballo' y 'la cantidad de agua equivalente a la altura de dos hombres', respectivamente. Se fundamenta en que los clasificadores numerales tienen un valor numérico, mientras que estas expresiones cuantitativas, si bien remiten a una cantidad, no se refieren a una cantidad discreta, como un numeral, sino a una medida aproximada.

Nuestro análisis se contrapone a la posición de Salas. En lo que sigue, intentamos justificar la existencia de clasificadores mensurales como parte de un sistema. En general, los clasificadores mensurales "crean una unidad de medida" 40 (Cheng y Sybesma (1999: 515), citados en Nomoto (2013: 8) y en Dalrymple y Mofu (2012: 253). En lenguas con clasificadores, así como en lenguas sin clasificadores, los numerales no pueden modificar directamente

\footnotetext{
38 Aparentemente, $<$ foc altæc $>$ 'hombro' y <altærr $>$ (<*altæc $>$ ) 'garganta' están relacionados.

39 <xllon> aparece atestiguado como 'comida' o 'pan', pero en este caso bien podría tratarse de algún verbo relacionado con 'comer'.

40 "create a unit of measure"
} 
nombres no contables como agua o aire (Nomoto 2013: 8). Un clasificador mensural "actúa como un masificador individuando porciones del nombre denotado"41 (Dalrymple y Mofu 2012: 253). En mochica, los clasificadores mensurales son $<$ ñofæn $>$, que significa literalmente 'hombre', y <col>, que Carrera (1644) traduce como 'caballo', pero que en realidad se refiere a 'llama'. El término $<$ ñofæn > como clasificador mensural es traducido como 'estado', como se puede apreciar en el ejemplo (10):

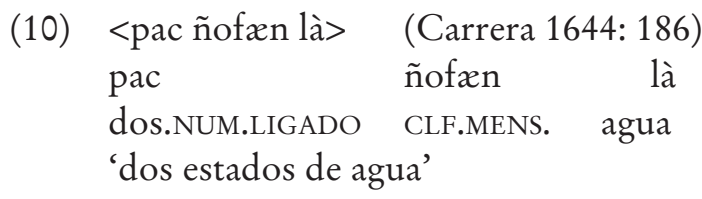

El estado era una unidad antigua de medida que se usaba en España, equivalente a una braza, que equivalía a dos varas o 1,6718 metros (Romero García 2004: 67). Se trataba de una medida longitudinal tomada de la estatura regular del hombre, usada para apreciar alturas o profundidades, y que solía calcularse en siete pies (DLE 2014).

Carrera (1644: 186) explica, además, el uso de <col> en el ejemplo (11):

$\begin{array}{lll}\text { <na col mang> } & \text { (Carrera 1644: 186) } \\ \text { na } & \text { col } & \text { mang } \\ \text { uno.NUM.LIGADO } & \text { CLF.MENS. } & \text { maíz } \\ \text { 'un caballo de maíz' } & \end{array}$

Cabe destacar que, antiguamente, entre las unidades de capacidad para áridos y granos en España se utilizaba la carga, que equivalía a la "capacidad de transporte de una acémila" (Carrión Arregui 1996: 61). La carga podía variar según el tipo de animal que cargara, pero, por lo general, correspondía a cuatro fanegas de Toledo (Carrión Arregui 1996: 65).

41 "acts as a massifier, individuating portions of the denotation of the noun". 
Es relevante mencionar que, en las descripciones de otras lenguas con clasificadores registradas en época colonial, también se encuentran clasificadores que se refieren a la cantidad de carga. Por ejemplo, en el maya yucateco, Beltrán ([1742] 1859) registra $<\mathrm{cuch}^{42}>$ referido a la carga que puede llevar una persona; esto es interesante porque en Mesoamérica no contaban con animales grandes de carga. De la misma manera, se observa en el Arte de la lengua japona, de Oyanguren ([1738] 2009), el clasificador registrado $<$ da $>$ (駄, da) 'carga de bestia' (de caballo) (cf. Eloranta 2012).

Además de constatar que parece generalizado el uso de unidades de capacidad relacionadas con la cantidad de carga que un animal o un ser humano puede transportar, podemos observar que en el sistema de clasificación numeral de la lengua mochica se establece una oposición líquido/sólido, que posiblemente fue el criterio semántico para clasificar los objetos que se deben categorizar o medir (agua/maíz).

Para entender de mejor manera el sistema de clasificación numeral mochica ${ }^{43}$ es adecuado dar una mirada breve a sistemas como los estudiados por Bender y Beller (2007a: 824). Estos autores identifican por lo menos cuatro tipos de sistemas entre las lenguas de Micronesia, a saber: clasificadores prototípicos, cuantificadores, clasificadores de potencia y clasificadores que adoptan simultáneamente tanto una función clasificadora como multiplicadora. En relación con la mayoría de clasificadores, explican que estos simplemente clasifican los objetos de referencia. Los cuantificadores introducen una nueva unidad de cuenta, como un grupo o manojo. Los clasificadores de potencia no clasifican, sino que multiplican, e indican un valor preciso que actúa como factor para el numeral al que se adjunta. Los clasificadores de potencia presentes en lenguas de Micronesia reemplazan a otros clasificadores e indican la nueva unidad de cuenta

\footnotetext{
42 El equivalente de <cuch > del maya yucateco en maya k'iche moderno es <ejqa'n>; así <jun ejqa'n si'> se refiere a la carga de maíz que una persona puede llevar (Sergio Romero, comunicación personal).

43 Un análisis del sistema más amplio puede consultarse en Eloranta (en prensa/c).
} 
independientemente del objeto contado ${ }^{44}$ (Bender y Beller 2007a: 824). A la vez, existe un tipo de clasificadores que adopta una función clasificadora como multiplicadora; estos proveen un valor preciso y están restringidos a ciertos objetos, como, por ejemplo, "diez cocos".

Bender y Beller (2007a: 821) establecen que los sistemas de cuenta específica se caracterizan por la combinación de dos rasgos: sus bases son unidades grandes de cuenta (función de multiplicación), y se aplican a solo a ciertos objetos específicos (función de especificidad de objeto). Bender y Beller (2006a; 2006b; 2007a: 825) proponen que la razón para que se apliquen estos sistemas en lenguas polinésicas y micronésicas fue para extender el sistema numeral original hacia números grandes y resultó de adaptaciones culturales. Otra importante observación de Bender y Beller (2006b: 42) contempla que el surgimiento de estos sistemas de cuenta específica pudo haberse desarrollado intencionalemente. Sin embargo, mientras sea imposible confirmar esto, la opción de un desarrollo a partir de un sistema de clasificación numeral es plausible.

El mochica tiene dos clasificadores numerales de pares ${ }^{45}$ a saber: $<$ felæp $>$ para contar aves y potos o recipientes para beber, y <luc> para platos o mates de comida, pepinos dulces y frutas o frutos. En este sentido, es importante mencionar que la diferencia entre los contenedores contados por estos clasificadores de pares radica tanto en su profundidad como en la consistencia de sus contenidos. Así, un poto puede contener líquidos, mientras que un mate puede contener alimentos sólidos. Según nuestro análisis, el origen de estos clasificadores parece ser más verbal que nominal. Los verbos implicados serían los verbos posicionales sentarse y estar de pie, respectivamente. Frente a esta propuesta de un origen verbal, Salas prefiere el lexema <loc $>$ 'pie' como la etimología de <luc> (2012:

\footnotetext{
44 "indicate the new counting unit independently of the object concerned" (Bender y Beller 2007: 824).

45 Algunas lenguas micronésicas — como el kiribati, el marshalés o el puluwatéstienen sistemas de cuenta en pares (Bender y Beller 2006b: 391). En puluwatés, se cuenta en pares el pescado, el árbol del pan (Artocarpus altilis) y los cocos (Elbert 1974: 111, citado en Bender y Beller 2006b: 391).
} 
158). Sin embargo, este análisis no responde satisfactoriamente a la dicotomía que la etimología de estar sentado/estar de pie sí cubre. Eso refleja, de alguna manera, el estado de los objetos que se encuentran contenidos en los recipientes mencionados.

La lengua mochica presenta también clasificadores numerales que sirven para contar en decenas. Las formas atestiguadas en Carrera (1644) son <pong $>$, <ssop $>$, <cyo(quixll) $>$ y <cæss $>$. El clasificador $<$ pong $>$ encuentra su etimología en la palabra mochica $<$ pong> 'piedra'. Según Carrera, <pong > sirve para contar personas, caballos, cabras, cañas y todo aquello que no es ni moneda ni frutas (1644: 183). El clasificador para decenas $<$ ssop $>$, que significa 'cuerda', 'soga' (Middendorf 1892: 68), se usa para contar monedas y días (Carrera 1644: 183). De acuerdo con los ejemplos registrados en los textos religiosos incluidos en la descripción gramatical de Carrera (1644), este último clasificador también era usado para contar conceptos abstractos de la fe católica como mandamientos, sacramentos, virtudes, etcétera.

La forma <cyoquixll> ha sido considerada hasta hoy como un clasificador (Adelaar en Adelaar y Muysken [2004] 2007: 343; Hovdhaugen 2004: 26; Salas 2012: 170) para contar decenas de frutas, mazorcas de maíz y otras cosas (Carrera 1644: 186). Sin embargo, al revisar los ejemplos de la gramática (Carrera 1644: 186), la única forma registrada parece ser simplemente $<$ cчo $>$, como en (12):

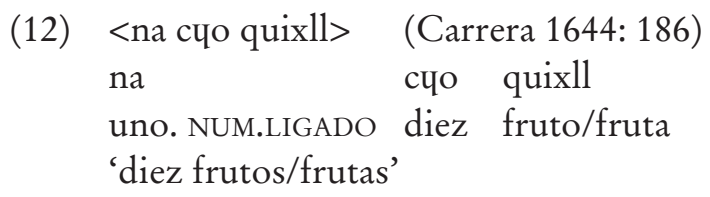

El clasificador para decenas <cæss> parece estar fosilizado. En el ejemplo registrado, solo sirve para contar días en grupos de diez (Carrera 1644: 186). Dejándolo de lado, los clasificadores para contar en decenas pueden ser sistematizados en un subsistema en el cual < pong> es una suerte de clasificador general que sirve para contar algunos objetos y todo lo que "no sea moneda ni fruta" 
(Carrera 1644: 183). Las monedas se cuentan usando <ssop>; y las frutas, con el clasificador $<$ cyo $>$. De esta manera, se puede asumir una dicotomía de distribución complementaria entre $<$ ssop $>$ y $<$ cyo $>$.

Además del sistema de clasificadores para decenas, la lengua mochica también presenta clasificadores que sirven para contar en centenas. Los términos para contar en centenas son dos: <palæc> (Carrera 1644: 184) y <chiæeng > (Carrera 1644: 186). En relación con $<$ palæc $>$, se carece de información acerca de los objetos que se pueden contar, pero su contraparte <chiæng > se encuentra registrada con la información acerca de los elementos que se pueden contar: frutos o frutas. Parece probable que estos dos clasificadores pudieran haber conformado parte de un susbsistema de distribución complementaria comparable con la dicotomía observada entre los clasificadores para decenas.

Ningún investigador del mochica ha contemplado < cunô $>$ como un clasificador numeral para millares. No hay mención acerca de los objetos contables con <cunô>, pero presumiblemente existió otro término para contar millares, que pudo haber servido para contar los objetos que no se podían contar con <cunô>. Se respondía así al patrón de distribución complementaria observado en los subsistemas de clasificadores de decenas y centenas.

Los clasificadores para contar decenas, centenas - y millaresexhiben una función multiplicadora clara. Por esta razón, a simple vista podrían ser vistos como clasificadores de potencia ${ }^{46} \mathrm{o}$ "power terms" como los conocidos en lenguas polinésicas. Sin embargo, ya que esta característica es también propia entre los clasificadores de un sistema de cuenta específica, se podría pensar que los clasificadores mochica conforman parte de un sistema de cuenta específica. La función de especificidad de objeto es esencial para definir un clasificador de cuenta específica. Esta segunda función no se manifiesta plenamente en el mochica. Los clasificadores del

\footnotetext{
46 Como ya observamos, los clasificadores de potencia no clasifican, sino que multiplican, indicando un valor preciso que actúa como factor para el numeral al que se adjunta.
} 
mochica no se restringen o no son específicos únicamente de un solo objeto. Estas unidades de cuenta, más bien, clasifican y agrupan sets de objetos de la manera en que un clasificador en sentido estricto lo haría.

A pesar de que estos clasificadores comparten algunos rasgos comparables con aquellos presentes en las lenguas estudiadas por Bender y Beller (2006a, 2006b, 2007a, 2007b), mantienen también sus propias características, razón por la cual no se puede observar este sistema como un sistema de clasificación numeral en sentido estricto, pero tampoco se puede asumir como un sistema de cuenta específica.

El interés en números grandes manifestado mediante los clasificadores mochica para contar en decenas y centenas puede haber estado motivado por razones socioeconómicas (Bender y Beller 2005, 2006a, 2006b, 2007a, 2007b). En este sentido, y teniendo en consideración la grandeza y el poder que alcanzó el imperio Sicán, ${ }^{47}$ no cabe duda de que un sistema con clasificadores que aceleren la cuenta era relevante.

Teniendo en cuenta el análisis presentado y al constatar, a la vez, que el sistema de clasificación numeral de la lengua mochica no puede ser entendido como un sistema de clasificación numeral en sentido estricto, nuestra propuesta lo determina como un sistema de clasificación numeral en fase de transición hacia un sistema de cuenta específica.

\subsection{Paradigmas de futuro}

El apartado 4.9. de Salas (2012), denominado Paradigmas de futuro, expone su análisis sobre las formas de las que se vale el mochica para expresar el futuro (182-185). Estas serían dos partículas adverbiales, <ca $>$ y $<$ chæm $>$, donde $<$ ca $>$ expresa el futuro simple; y $<$ chæm $>$, el futuro de obligación. Además, Salas presenta $<\mathrm{tæc}>$ como el tercer medio para expresar futuro en mochica.

\footnotetext{
47 Es muy probable que por lo menos algunos miembros de las dinastías Sicán hablaran mochica (Shimada y otros 2005: 64; Shimada 2009: 8).
} 
Podemos observar que Carrera considera que <-chæm> es similar al futuro latino en -rus (1644: 39 y 62). De manera similar, el cholón, otra lengua andina extinta, presenta el nominalizador $<-$ lam >, que refiere a un evento en el futuro u obligación (AlexanderBakkerus 2005: 255; 2011: 202). En su descripción gramatical del cholón, De la Mata también compara <-lam> con el participio de futuro -rus ([1748] 2007: 135). Se puede determinar, por tanto, que ambos misioneros intentaron subsumir el tiempo y la modalidad que reconocían en $<-$ lam $>$ y en $<-$ chæm $>$ (futuro y obligación) en el término del participio de futuro en - rus.

El tercer elemento para formar construcciones de futuro es $<$ tæc $>$, y Salas lo identifica como el verbo irregular ir. ${ }^{48}$ El verbo ir ya se encuentra consignado como tal en Carrera (1644: 147), y quizás sea esta la fuente sobre la cual Salas basa su propuesta de $<\mathrm{tæc}>$ como la forma infinitiva del verbo para formar construcciones del mochica. No obstante, en Carrera el paradigma de futuro imperfecto lleva como raíz verbal únicamente $<\mathrm{t}->$ con los clíticos correspondientes (1644: 49). En la misma línea, la propuesta de Hovdhaugen para explicar el paradigma de futuro asume que existe un verbo de futuro $<\mathrm{t}->(2004: 46)$. Consideramos que es muy probable que, efectivamente, se trate del verbo $i$, cuya raíz sería $<\mathrm{t}->$.

\section{Comentario final}

En el aspecto formal, la obra de Salas (2012) presenta ciertas deficiencias. El tesón puesto en Etimologías mochicas queda opacado por la falta de glosas lingüísticas, lo que se puede considerar un gran problema. Mediante ejemplos glosados se podrían evitar confusiones y también se llegaría a estandarizar el texto a un nivel compatible con el de trabajos lingüísticos que tratan de otras lenguas del mundo. El texto, a veces, se muestra denso, difícil de seguir y retórico. Se podría obtener un estudio con explicaciones menos coloridas, pero con más contenido lingüístico. El libro y los análisis

48 Salas no menciona que Hovdhaugen (2004) ya había reconocido los mismos tres medios para expresar el futuro que él propone. 
se pierden en el texto escrito y no son útiles para lingüistas que, sin saber español, podrían acercarse a la obra y leer, a través de las glosas, lo que el autor desea decir.

Otra de las inconsistencias en la obra de Salas es cierta imprecisión en sus citas. Después de consultadas sus fuentes, nos da la impresión de que ha realizado una lectura equivocada de ellas. Lo hemos podido observar en los casos concretos de las citas del registro de <pitš> 'pallar' (Brüning [1905-1924] 2004: 47). En la edición del Mochica Wörterbuch de Brüning realizada por Salas (2004), se recoge la información que se encuentra en los manuscritos originales de Brüning, conocidos como Mochica Wörterbuch I y II, consignados en la biblioteca del Museo Etnológico de Hamburgo (Museum für Völkerkunde Hamburg) como Brü. 1.34 y Brü. 1.35, respectivamente. En Brü. 1.35, página 53, se registra < pitš> y en Brü. 1.34 , sin numerar, se consigna <pätši>. Sin embargo, Salas ofrece una tabla con un corpus de testimonios de registro de 'pallar' o 'frejol' que incluye supuestamente todos los aportados, pero < pitš> no aparece (2012: 56). En relación con las citas de Brüning, también se aprecia este defecto en el caso del término para 'muchacha', que Salas asevera encontrar en las libretas del alemán tšaš y tšaša (Salas 2012: 71). El segundo término no lo pudimos encontrar.

Más o menos en la misma dirección, otro defecto que también se manifiesta es la ausencia de mención de la fuente de información que pudo haber inspirado a Salas para hacer ciertas afirmaciones. A través de la lectura de sus textos, bien se podría asumir que sus conclusiones son meramente fruto de sus propias reflexiones, ya que no menciona trabajos anteriores de autores que tratan el mismo tema. Un ejemplo de este problema está presente en 3.4, donde se observa de cerca su análisis del paradigma de futuro y no menciona las intuiciones de Hovdhaugen (2004).

Otro problema que enfrenta Salas en su trabajo es la falta de sistematización de sus análisis. Por ejemplo, en relación con la posesión nominal, no observa las diferentes estructuras posesivas como un sistema, sino que establece características de algunos nombres guiándose por determinados criterios — como estar poseído o no-, 
y no contempla campos semánticos o marcas morfológicas que agrupan ciertos nombres. Desde un análisis falto de sistematización se incurre, pues, inevitablemente, en errores.

Comentar un trabajo tan lleno de información sobre el mochica como este es un verdadero reto, que se complica aún más al tener que enfrentarse a una persona tan versada en la materia. Este ensayo surgió como una reflexión en torno al trabajo de Salas (2012), y a pesar de que parezca tener un matiz negativo y de posición contraria a sus propuestas, se debe considerar, en primer lugar, que cualquier espacio para comentar y criticar cualquier trabajo suyo resulta demasiado limitado. Por tal motivo, hemos optado por resaltar ciertos aspectos cuestionables observados desde una perspectiva distinta. El esmero del autor, que implica numerosos años abocados al mochica, siempre será un aliciente y un ejemplo para todo aquel que se aproxime al estudio de esta lengua. Definitivamente, cualquier interesado en estudiar y profundizar en el conocimiento de esta lengua tiene que volver los ojos hacia los textos de José Antonio Salas, porque es quien tiene el mérito de ser uno de los primeros en haberle dedicado buena parte de sus reflexiones a esta lengua.

Los comentarios aquí expuestos deben ser observados como un intento de entrar en un diálogo de tipo académico entre dos aproximaciones distintas. Lo dicho aquí no debe verse como algo definitivo, sino más bien como ideas en proceso de maduración.

Referencias bibliográficas

Academia de la Llingua Asturiana

[2010] 2015 Diccionariu de la Llingua Asturiana.

AdELAAR, Willem

[2004] Yurumangui. En Willem Adelaar y Pieter C. Muysken. The 2007a languages of the Andes. Cambridge: Cambridge University Press, 60-61.

[2004] The Mochica language. En Willem Adelaar y Pieter C. Muysken. 2007b The languages of the Andes. Cambridge: Cambridge University Press, 319-350. 
Adelaar, Willem y Pieter C. Muysken

[2004] 2007 The languages of the Andes. Cambridge: Cambridge University Press.

Aikhenvald, Alexandra

2000 Classifiers: a typology of noun categorization devices. Oxford: Oxford University Press. https://doi.org/10.1093/acprof:o so/9780199660223.003.0001

Aikhenvald Y. Alexandra y R. M. W. Dixon (Eds.)

2013 Possession and Ownership A Cross-Linguistic Typology. Oxford: Oxford University Press.

Alexander-Bakkerus, Astrid

2002 "Nominal Morphophonological processes observed in Pedro de la Mata's Arte de la Lengua Cholona (1748)". In Mily Crevels, Simon van de Kerke, Sergio Meira y Hein van der Voort (Eds.). Current Studies on South American Languages [Languages of Latin America, 3], 103-110. Leiden: Research School of Asian, African, and Amerindian Studies (CNWS).

2005 Eighteenth-Century Cholón. PhD Dissertation. Utrecht: LOT.

Allan, Keith

1977 Classifiers. Language, volume 53, number 2, 285-311. Linguistic Society of America. Consultado: 31 de marzo de 2016. <http://www.jstor.org/stable/413103> . https://doi. org/10.1353/lan.1977.0043

2001 Natural Language Semantics. Oxford: Blackwell Publishers.

Álvarez FernándeZ-Novo, Fernando

1998 Vocabulario de Riosa. Uviéu: Academia de la Llingua Asturiana.

Álvarez López, Alejandro

2005 El burón: la jerga de los vendedores y albarderos ambulantes de Forniella. Instituto de Estudios Bercianos-Academia de la Llingua Asturiana. Ponferrad: Peñalba Impresión.

Amaro Gamboa, Jesús

1999 Vocabulario del nayeísmo en la cultura de Yucatán. Segunda edición, por Miguel A. Güémez Pineda. Yucatán: Ediciones de la Universidad Autónoma de Yucatán. 
Амека, Felix Kofi

1991 Ewe: Its grammatical constructions and illocutionary devices. Australian National University. PhD Dissertation.

1995 The linguistic construction of space in Ewe.Cognitive Linguistics. Volume 6, Issue 2-3, 139-182. https://doi. org/10.1515/cogl.1995.6.2-3.139

1996 “Body parts in Ewe”. En Chappell, Hilary y William McGregor (Eds.). The Grammar of Inalienability, A Typological Perspective on Body Part Terms and the Part-Whole Relation. Berlin-New York: Mouton de Gruyter, 783-840. https://doi. org/10.1515/9783110822137.783

AnÓnimo (Blas Valera)

1586 Arte, y Vocabulario en la Lengua General del Perú llamada Quichua en la lengua Española. El mas copioso y elegante que hasta agora se ha impresso. Lima: Antonio Ricardo.

1603 Gramática y vocabolario en la lengva general del Perv llamada Quichua, y en la lengua Española. Sevilla: en casa de Clemente Hidalgo.

1604 Vocabulario en la lengva general del Perv llamada Quichua, $y$ en la lengua Espanola. Nuevamente emendado y añadido de algunas cosas que faltauan por el Padre Maestro Fray Iuan Martinez Cathedratico de la lengua. De la Orden de San Agustín.

1614 Arte, y vocabolario en la lengva general del Perv llamada Quichua, y en la lengua Española. Lima: Francisco del Canto, editor.

[1585] 2014 Arte y vocabulario en la lengua general del Perú, edición interpretada y modernizada de Rodolfo Cerrón-Palomino, con la colaboración de Raúl Bendezú Araujo y Jorge Acurio Palma. Lima: Pontificia Universidad Católica del Perú, Instituto Riva-Agüero.

Arámbulo Palacios, Edmundo

1995 Diccionario de piuranismos. Lima: Concejo Provincial de Piura.

Arona, Juan de [seudónimo de Pedro Paz Soldán y Unanue]

1884 Diccionario de peruanismos. Ensayo filológico. Lima: Librería Francesa Científica J. Galland.

Asociación de Academias de la Lengua Española

2010 Diccionario de americanismos. Madrid: Santillana. 
Augusta, Félix José de

1916 Diccionario araucano-español, español-araucano.

Beltrán de Santa Rosa María, Pedro

[1742]1859 Arte del Idioma maya reducido a sucintas reglas y Semilexicon Yucateco. Segunda edición. Mérida de Yucatán: Imprenta de J. D. Espinosa. https://doi.org/10.5479/ sil.266870.39088005811658

Bender, Andrea y Sieghard Beller

2005 The Cognitive Advantages of Counting Specifically: An Analysis of Polynesian Number Systems. Proceedings of the Annual Meeting of the Cognitive Science Society 27.

2006a "Numeral Classifiers and Micronesian Languages: Common Roots and Cultural Adaptations". En Oceanic Linguistics, Vol. 45, N. ${ }^{\circ}$ 2, December, University of Hawai'i Press, 380-403. https://doi.org/10.1353/ol.2007.0000

2006b “Fanciful' or genuine? Bases and high numerals in Polynesian number systems”. Journal of the Polynesian Society, 115 (1), 7-46.

2007a Numeral Classifiers in Specific Counting Systems: Cultural context, Linguistic Principles, and Cognitive Implications. En D. S. MacNamara y J.G Trafton (Eds.). Proceedings of the Twenty-Ninth Annual Conference of the Cognitive Science Society, 821-826. New York: Erlbaum.

2007b "Counting in Tongan: The traditional number systems and their cognitive implications". Journal of Cognition and Culture, 7, 213-239. https://doi.org/10.1163/156853707X208495

Brack EgG, Antonio

1999 Diccionario enciclopédico de plantas útiles del Perú. Cusco: Centro de Estudios Regionales Andinos Bartolomé de Las Casas.

BRIL, Isabelle

2013 "Ownership, part-whole, and other possessive-associative relations in Nêlêmwa (New Caledonia)". En Y. Alexandra Aikhenvald y R. M.W. Dixon (Eds.). Possession and Ownership A Cross-Linguistic Typology. Oxford: Oxford University Press, 65-89. https://doi.org/10.1093/acprof:o so/9780199660223.003.0002 
BRÜNING, Hans Heinrich

[1905-1924]Mochica Wörterbuch-Diccionario mochica castellano/ 2004 castellano-mochica. José Antonio Salas García (Ed.). Lima: Universidad de San Martín de Porres, Escuela Profesional de Turismo y Hotelería.

1905-1924 BRÜ 1.34 Mochica Wörterbuch I, manuscrito conservado en la Biblioteca del Museo Etnológico de Hamburgo (Museum für Völkerkunde Hamburg).

1905-1924 BRÜ 1.35 Mochica Wörterbuch II, manuscrito conservado en la Biblioteca del Museo Etnológico de Hamburgo (Museum für Völkerkunde Hamburg).

Calancha, Antonio de la

1638 Coronica Moralizadora del Orden de San Avgrstine nel Perv, con svcesos egenplares en esta monarqvia. Vol I. Barcelona: Lacavalleria.

Carrera Daza, Fernando de la

$1644 \quad$ Arte de la lengra yonga de los valles del Obispado de Truxillo del Peru, conon Confessonario, y todas las Oraciones Christianas, traducidas en la lengua, y otras cosas. Lima: Joseph Contreras.

Carrión Arregui, Ignacio María

1996 Los antiguos pesos y medidas guipuzcoanos (The old weights and measures of Gipuzkoa). [1136-6834 (1996), 24; 59-79]

Cerrón-Palomino, Rodolfo

1995 La lengua de Naimlap (reconstrucción y obsolescencia del mochica). Lima: Pontificia Universidad Católica del Perú.

2008 Voces del Ande. Ensayos sobre onomástica andina. Colección Estudios Andinos. Lima: Fondo Editorial de la Pontificia Universidad Católica del Perú.

Chappell, Hilary y William Mc Gregor

1996 "Prolegomena to a theory of inalienability". En The Grammar of Inalienability, A Typological Perspective on Body Part Terms and the Part-Whole Relation. Eds., Hilary Chappell y William Mc Gregor. Berlin-New York: Mouton de Gruyter, 3-30. https://doi.org/10.1515/9783110822137.3

Сово, Bernabé

[1653] 1956 Historia del Nuevo Mundo. Obras del P. Bernabé Cobo. Madrid: BAE, Ediciones Atlas. Tomos I-II. 
Corominas, Joan

[1954] 1974 Diccionario crítico etimológico de la lengua castellana (Biblioteca Románica Hispánica, V. Diccionarios, 1). Reimpresión. Madrid: Gredos.

DahL, Östen y Maria KopTJEvSKaJA-TAmM

1998 "Alienability splits and the grammaticalization of possessive constructions”. En Haukioja T. (Ed.). Papers from the XVIth Scandinavian Conference of Linguistics. Turku: Turun Yliopisto/Åbo Akademi, 38-49.

2001 "Kinship in grammar". En Irene Baron, Michael Herslund y Finn Sørensen (Eds.) Dimensions of Possession. Amsterdam/ Philadelphia: John Benjamins Publishing Company, 201-225. https://doi.org/10.1075/tsl.47.12dah

Dalrymple, Mary y Mofu, Suriel

2012 "Plural Semantics, Reduplication, and Numeral Modification in Indonesian”. Journal of Semantics, 29 (2), 229-260. https:// doi.org/10.1093/jos/ffr015

De la Mata, Pedro

[1748] 2007 Arte de la lengua cholona. Astrid Alexander-Bakkerus (Ed.), Madrid: Iberoamericana, Vervuert.

ELORANTA, Rita

2012 Un análisis historiográfico de la categoría de clasificador numeral en ocho gramáticas coloniales de tradición bispánica. Tesis de maestría. Universidad de Helsinki.

e. p. a Mochica lexical and grammatical nominalization.

e. p. b Posesión nominal en la lengua mochica, enviado a Proceedings of the Eighth Conference on Missionary Linguistics en la Pontificia Universidad Católica del Perú (PUCP), marzo 2014. Lima: Fondo Editorial PUCP.

e. p. c Mochica numeral classifier system.

Epps, Patience

2008 A Grammar of Hup. Berlin: Walter de Gruyter. https://doi. org/10.1515/9783110199079

FERnÁNDEZ Garay, Ana

2004 "Aspectos semánticos-cognitivos de la posesión en tehuelche". En UniversSOS 1, 43-59. 
FigueREDO, Juan de

[1700] 1754 Vocabulario de la lengua chinchaisvyo, y algunos modos mas vsados de ella, que compuso y añadio al antiguo. En Torres Rubio. Arte y vocabulario de la lengua quichua general de los Indios del Perú. Lima: Imprenta de la Plazuela de San Christoval. (Vocabulario Indico Chinchaisuyo 54v57v-Vocabulario Castellano, Indico Chinchaisuyo 57r-59r). Lima: Imprenta de la Plazuela de San Cristóbal.

Franco Grande, Luis X.

1968 Diccionario galego-castelán e vocabulario castelán-galego. Santiago de Compostela: Editorial Galaxia.

Gonçalez Holguín, Diego de

1608 Vocabvlario de la Lengua General de todo el Perv llamada lengua Qquichua, o del Inca. Ciudad de los Reyes [Lima]: Francisco de Canto.

Haspelmath, Martin

2006 "Explaining alienability contrasts in adnominal possession: economy vs. Iconicity”. Syntax of the World's Languages 2, University of Lancaster.

HeIne, Bernd

1997 Possession. Cognitive Sources, Forces and Grammaticalization. Cambridge: Cambridge University Press. https://doi. org/10.1017/CBO9780511581908

Hovdhaugen, Even

2004 Mochica. München: Lincom.

Instituto de Investigación Rafael Lapesa de la ReAl Academia Española 2013 Corpus del Nuevo diccionario histórico (CDH) [en línea]. <http://web.frl.es/CNDHE> [Consultado: 16/09/2017]

Kockelman, Paul

2007 “Inalienable possession and personhood in a Q'eqchi'. Mayan community”. Language in Society 36, 343-369. https://doi. org/10.1017/S0047404507070170

KÖVeCSEs, Zoltán

2006 Language, Mind, and Culture A Practical Introduction. Oxford: University Press. 
LeHmann, Christian

2003 Possession in Yucatec Maya. Second, revised edition. Assidue Arbeitspapiere des Seminars für Sprachwissenschaft der Universität Erfurt. Erfurt: Seminar für Sprachwissenschaft der Universität

León Barandiarán, Augusto Domingo Roberto y Rómulo Paredes

$1934 \quad$ A golpe de arpa. Folklore lambayecano de bumorismo y costumbres. Lima.

Malkiel, Yakov

1993 Etymology. Cambridge: Cambridge University Press. https:// doi.org/10.1017/CBO9780511611773

Michael, Lev

2013 "Possession in Nanti”. En Alexandra Aikhenvald Y. y R. M. W. Dixon (Eds.) Possession and Ownership A Cross-Linguistic Typology. Oxford: Oxford University Press, 149-166. https:// doi.org/10.1093/acprof:oso/9780199660223.003.0006

Middendorf, E. W.

1892 Das Muchik oder Chimu-Sprache. Die einheimischen Sprachen Perus. Vol. VI. Leipzig: F. A. Brockhaus.

Nichols, Johanna

1988 On alienable and inalienable possession. En W. Shipley (ed.), In Honor of Mary Haas: From the Haas Festival Conference on Native American Linguistics, Berlin: Mouton de Gruyter, 557-609.

Nомото, Hiroki

2013 Number in Classifer Languages. A dissertation submited to the Faculty of the Graduate School of the University of Minnesota.

Oyanguren de Santa Ynés, Melchor

[1738] 2009 Arte de la lengua japona, dividido en quatro libros segun el arte de Nebrixa. Con algunas voces proprias de la escritura, y otras de los lenguages de Ximo, y del Cami, y con algunas perifrases, y figuras. Mexico: Joseph Bernardo de Hogal. Estudio y edición de Otto Zwartjes, Madrid/Frankfurt am Main: Iberoamericana/Vervuert. 
Puig y TARrats, Esteban

[1985] 1995 Breve diccionario folclórico piurano. 2. ${ }^{\text {ed. Lima: Universidad }}$ de Piura.

Real Academia Española

2014 Diccionario de la lengua española. 23. a ed. Madrid: Espasa.

s/f Corpus diacrónico del español (CORDE). Consultado: 16 de setiembre de $2017<$ http://www.rae.es>.

$\mathrm{s} / \mathrm{f} \quad$ Corpus de referencia del español actual (CREA). Consultado: 16 de setiembre de 2017 <http://www.rae.es>.

Rojas-Berscia, Luis Miguel y Sâm Ghavami-Dicker

2015 “Teonimia en el Alto Amazonas, el caso de Kampunama”. Escritura y Pensamiento. XVIII, 36, 117-145.

Romero García, Rafael Eugenio

2004 "Medidas antiguas españolas. Breve compendio de las medidas antiguas utilizadas en las diferentes regiones y provincias españolas”. En Técnica Industrial 254.

Salas García, José Antonio

2008 "Formas ligadas en los numerales del mochica". Lexis. XXXII, 1, 147-158.

2012 Etimologías mochicas. Lima: Academia Peruana de la Lengua.

Santo Thomas, Domingo

1560 LEXICON o Vocabulario de la lengua general de los Indios del PERV. Valladolid: Francisco Fernández de Córdoua.

SHIMADA, Izumi

2009 Who were the Sican? Their development, characteristics and legacies. English text of the introductory chapter (pp. 25-61) of the 2009 exhibit catalog entitled The Golden Capital of Sicán that was edited by Izumi Shimada, Ken-ichi Shinoda and Masahiro Ono, Tokyo Broadcasting System, Tokyo. Published in Japanese.

Shimada, Izumi; Ken-ichi Shinoda, Steve Bourget, Walter Alva y Santiago UCEDA

2005 "MtDNA analysis of Mochica and Sicán populations of pre-Hispanic Peru”. David M. Reed (ed.). Biomolecular Archaeology: Genetic Approaches to the Past. Carbondale IL: Center for Archaeological Investigations, Southern Illinois University, 61-92. 


\section{Terreros y Pando, Estevan}

1786 Diccionario castellano con las voces de ciencias $y$ artes $y$ sus correspondientes en las tres lenguas francesa, latina e italiana. Tomo I. Madrid: Imprenta de la Viuda de Ibarra, hijos y compañía.

Torero Fernández, Alfredo Augusto

2002 Idiomas de los Andes. Lingüística e historia. Travaux de l'Institut Français d'Études Andines 162. Lima: IFEA y Editorial Horizonte.

Torres Rubio, Diego

$1700 \quad$ Arte y vocabulario de la lengua quichua general de los Indios del Perú. Lima: Imprenta de la Plazuela de San Christoval. (Vocabulario Indico Chinchaisuyo 54v- 57v-Vocabulario Castellano, Indico Chinchaisuyo 57r-59r).

YAP, Foong Ha; Karen GrUnOw-HÅrSTA y Wrona JANICK

2011 "Nominalization strategies in Asian Languages". In Foong Yap, Karen Grunow-Hårsta y Janick Wrona (Eds.). Nominalization in Asian Languages, Diacbronic and typological perspectives. Amsterdam/Philadelphia: John Benjamins, 1-57. https://doi. org/10.1075/tsl.96.01yap

Zevallos QuiÑones, Jorge

1992 Los cacicazgos de Trujillo. Trujillo: Fundación Alfredo Pinillos Goicochea. 